\title{
PROVAÇÕES NO PARAÍSO? REPRESENTAÇÕES E DISCURSOS SOBRE CRIMINALIDADE URBANA EM MUNICÍPIOS DO INTERIOR DO RIO DE JANEIRO: o caso de Angra dos Reis
}

Fabiano Dias Monteiro ${ }^{1}$

\section{Resumo}

O presente artigo tem por objetivo investigar o impacto da instalação das Unidades de Polícia Pacificadora do Rio de Janeiro (UPPs) sobre as dinâmicas criminais da cidade de Angra dos Reis, no litoral sul. Por outro turno, pretendo compreender como a crença na migração de traficantes de drogas da capital pode afetar a institucionalização de políticas de prevenção à violência no município.

Palavras-chave: Unidade de Polícia Pacificadora; Prevenção da Violência; Rede de Proteção Social

\begin{abstract}
The article aims to investigate the impact of the installation of the Rio de Janeiro Pacifying Police Units (UPPs) on the criminal dynamics of the city of Angra dos Reis, on the south coast. On the other hand, I intend to understand how the belief in the migration of drug traffickers in the capital can affect the institutionalization of violence prevention policies in the municipality.
\end{abstract}

Keywords: Pacifying Police Units; Violence Prevention; Social Protection Network

\footnotetext{
${ }^{1}$ Doutorado em Antropologia Cultural (PPGSA/UFRJ). Mestre em Sociologia pelo (PPGSA/UFRJ) e Bacharel em Ciências Sociais (ICHF/UFF). Foi Bolsista PDR da Fundação de Amparo à Pesquisa do Rio de Janeiro entre os anos de 2011-2014 e atualmente Professor Adjunto do Departamento de Geografia e Políticas Públicas do IEAR da Universidade Federal Fluminense.
} 


\section{Introdução}

Diante dos desafios impostos por duas frentes de pesquisa - uma relacionada a um projeto de Inovação Científica (PIBINOVA) e a outra a um Projeto de Extensão (Conjuntura Costa Verde), ambas desenvolvidas no âmbito da Universidade Federal Fluminense, busquei perscrutar, entre os anos de 2016 e 2017, recursos institucionais e soluções inovadoras capazes de dirimir os níveis de violência e criminalidade no município de Angra dos Reis, no sul fluminense.

Do alto de um vasto "desconhecimento" sobre a vida social da região, contei com o apoio de outros pesquisadores para delinear um cronograma inicial, que passava por um levantamento dos indicadores de criminalidade violenta na região, bem como por uma abordagem de caráter qualitativo, envolvendo atores estratégicos (governamentais ou não) inseridos em rotinas e ações com detectável potencial de contribuição para políticas de prevenção da violência.

Logo nos primeiros contatos com os entrevistados, o discurso da escalada da violência no município fez-se perceptível. Assim como sua associação às investidas do Governo do Estado do Rio de Janeiro contra a ação de traficantes nas favelas da capital, através da sua ocupação permanente pela Polícia Militar. A suposta escalada da violência angrense, era, destarte, tomada como efeito colateral das tentativas de contenção da violência nas favelas cariocas.

Diz o adágio que uma fantasia, quando repetida por diversas vezes, tende a tornar-se realidade. Essa sabedoria popular parecia se impor diante de mim e dos meus colaboradores de pesquisa no início dessa jornada.

No ano de 2008, surge um novo quadro referencial nos debates e estudos sobre a violência no estado do Rio de Janeiro: a instalação das Unidades de Polícia Pacificadora (UPPs) em favelas da capital. Assumindo o status de "problemática obrigatória" (Bourdieu, 2015) nos assuntos de segurança, a instalação das UPPs levantou esperanças e críticas ao longo de sua implementação.

Longe de poder ser definida uma "política pública de segurança", no estrito senso do termo, as UPPs apresentaram-se como uma ação de ocupação permanente, pela Polícia Militar, de áreas conflagradas da cidade, afetadas pelas atividades do tráfico de drogas ou das milícias².

\footnotetext{
${ }^{2}$ Há de se frisar que o projeto das UPP teve suas ações mais concentradas em áreas impactadas pelo tráfico do que nas chamadas "áreas de milícias".
} 
Sem definir - ou, pelo menos, sem esclarecer para o grande público- os parâmetros das ocupações/intervenções, as dotações/impactos orçamentários, os mecanismos de avaliação do projeto e as projeções futuras, a partir dos resultados estimados (e que resultados seriam esses), não tardou para que setores da academia e da sociedade civil organizada levantassem dúvidas sobre os propósitos e sobre a sustentabilidade (ou mesmo viabilidade) do projeto, apesar da visibilidade cedida pela mídia e pelo empenho dos governantes em divulgar seus aspectos positivos (MACHADO, 2010).

Inquestionavelmente, houve aspectos positivos, nas primeiras intervenções. As ações, que começaram a ser desenvolvidas nas favelas da Zona Sul (a primeira ocupação se deu no Morro de Santa Marta, em Botafogo), espraiando-se por comunidades do Centro, Maciço Tijucano, Zona Oeste e Zona Norte, conseguiram reduzir os níveis de violência letal nestas áreas, mormente por diminuir o número de confrontos armados entre traficantes (CANO, et. al., 2012).

Por outro turno, estima-se que tenha crescido o nível de conflito entre policiais e moradores, principalmente em função das abordagens feitas pelos agentes, não raro, tomadas como abuso de poder ou violação de direitos. A Secretaria de Segurança Pública, reportando-se diretamente ao gabinete do então Governador Sérgio Cabral, teve dificuldades em criar e fortalecer canais de diálogo entre a polícia e a população residente nas favelas. Tornou-se evidente a necessidade de intervenções governamentais no atendimento de serviços básicos, nas áreas de habitação, urbanização, saúde e educação e a Polícia Militar se viu impelida a iniciar uma série de ações pontuais e desencontradas (ainda que "bem-intencionadas") no atendimento de demandas que deveriam ser competência dos órgãos da rede de proteção social, como: distribuição de cestas básicas; implementação de projetos esportivos; mediação de cunho patrimonial; etc., dando origem a um campo de atuação que tinha como ator central um personagem que o pesquisador César Teixeira (2015) nomeou de "policial social"3.

Além das fragilidades já apontadas, havia outras, ainda mais decisivas, que se impunham ao "programa" das UPPs. O crescimento do projeto, que chegou a contar com 38 unidades na região metropolitana do Rio, exigia um ritmo acelerado na contratação e formação de novos policiais, o que fragilizava, progressivamente, a qualidade de capacitação dos agentes para o desempenho da

\footnotetext{
${ }^{3}$ Dados os propósitos e limites do presente artigo não aprofundarei a discussão sobre a relação entre a pacificação e a disponibilização de serviços básicos pelo poder público nas favelas do Rio. Há de mencionar o papel desempenhado, parcialmente, pela chamada UPP Social, a saber, iniciativa desenvolvida e elaborada pela Secretaria de Estado de Assistência Social e Direitos Humanos, entre os anos de 2010 e 2011 que visava o desenvolvimento de ações transversais nas comunidades, facilitando o diálogo entre entidades locais - sociedade civil organizada - e o poder público. Após mudanças no staff da Secretaria de Assistência, decorrente do processo eleitoral do período, o projeto foi transferido para o Instituto Pereira Passos, da Prefeitura do Rio de Janeiro.
} 
nova função e, principalmente, comprometia o orçamento destinado à Segurança Pública a gastos quase exclusivos com recursos humanos.

E plausível supor que tal comprometimento do orçamento tenha fragilizado a logística por trás da instalação e funcionamento das novas unidades. Já em 2012, com o episódio da morte da soldado Fabiana Aparecida de Souza ${ }^{4}$, de 30 anos, num ataque conduzido por traficantes, no Morro do Alemão, vicejavam, na imprensa, críticas e denúncias a respeito das condições de trabalho vivenciadas pelos policiais nessas unidades. Questionava-se desde as condições físicas das instalações - algumas delas muito precárias, resumidas a um agrupamento de caráter provisório em contêineres - até a qualidade dos equipamentos de trabalho (coletes de proteção, armamentos, viaturas, etc.).

Por fim, crescia a insatisfação de setores da sociedade com a diminuição do volume de prisões e apreensões de armas e drogas durante os processos de ocupação. A incapacidade das polícias militar e civil em desarticular as facções criminosas e prender seus líderes - e certamente a imagem mais presente e dramática que sintetiza esse discurso é a da "fuga em massa" de traficantes pela mata na ocupação do Complexo do Alemão, em 2010 - traduzir-se-ia num suposto "êxodo" de criminosos para municípios da Baixada Fluminense e do interior do estado.

Embora a Secretaria de Segurança tenha sido ágil, ainda no ano de 2010, em tentar desmistificar essa percepção ${ }^{5}$, não tardou para que ela ganhasse contornos de "verdade", constituindo-se, assim, em vetor explicativo para o suposto crescimento da criminalidade violenta em municípios distantes da capital.

Neste artigo, será tratado do caso do município de Angra dos Reis, a partir de uma análise dos principais indicadores de criminalidade violenta e dos discursos emitidos pela imprensa local e por operadores do poder público atuantes em áreas da administração afeitas à prevenção da violência.

\section{"Paraíso perdido" ou as vicissitudes do progresso? Dinâmicas sociais e econômicas de Angra dos Reis}

Dotada de beleza natural exuberante, fincada entre a Mata Atlântica e o mar, Angra dos Reis é uma das cidades mais antigas do Brasil, tendo sido fundada em 1502. Inserida no ciclo canavieiro, durante o período colonial, desponta como ponto estratégico para a escoação da produção de café

\footnotetext{
${ }^{4}$ Ver matéria do Portal G1: “Corpo de PM morta em ataque à UPP é enterrado nesta quarta em Valençca", de 25/07/2012. ${ }^{5}$ Ver matéria do Portal G1: "Traficantes expulsos do Rio migram para outras cidades”, de 29/01/2010.
} 
vinda do Vale do Paraíba, já no período do Império, tendo, outrossim, a pesca como uma de suas principais atividades até o século XX (ABREU, 1994).

Sendo, nos dias de hoje, um ponto de referência no roteiro turístico internacional, - atraindo tanto adeptos do turismo comercial, que ali chegam em busca do conforto de requintados resorts, como entusiastas do chamado "ecoturismo de base comunitária" - Angra dos Reis divide sua imagem de "refúgio tropical" com a de uma cidade amplamente impactada pela modernização.

Situada geograficamente entre as duas forças econômicas do país (São Paulo e Rio de Janeiro), compondo a chamada "Região Costa Verde", ao lado de Mangaratiba e Paraty, no sul fluminense, a cidade foi estratégica para empreendimentos de caráter desenvolvimentista na segunda metade do século $\mathrm{XX}$, sobretudo no que diz respeito à produção de energia e ao desenvolvimento da indústria naval. Dentre eles: a instalação do Estaleiro Verolme, nos anos 1960 e do terminal marítimo da Petrobrás (1977); a abertura da Rodovia Rio-Santos (1972) e a construção das usinas nucleares de Angra I (1972) e Angra II (1985) (TCE/FIRJAN, 2015).

Tais incrementos econômicos deixaram marcas indeléveis na vida do município. $\mathrm{Na}$ transição de região voltada para a agricultura de subsistência e pesca artesanal para polo industrial, Angra dos Reis teve sua população aumentada em quase 10 vezes entre os anos 1940 e os dias atuais. Apenas entre os anos de 2000 e 2010 a população da cidade aumentou em 50.264 habitantes. Neste mesmo ano, a população urbana era da ordem de 163.290 habitantes contra 6.221 pessoas vivendo no meio rural (IBGE, 2010).

Em um processo de rápido crescimento populacional e urbanização é compreensível a emergência de novos e grandes desafios para a administração pública. No caso de Angra dos Reis, a favelização foi um deles. Ainda segundo o censo de 2010, de uma população residente de 169.247 habitantes, 60.009 encontravam-se situados em aglomerados subnormais ${ }^{6}$.

A variação de postos de emprego, sobretudo nos setores da indústria e da construção civil, revela-se também preocupante. Na indústria, após um amento de cerca de 3.500 postos, entre os anos de 2005 e 2015, observa-se a retração na ordem de 4.000 postos entre os anos de 2015 e 2017. Na construção civil observamos movimento análogo. Após um incremento de cerca de 3.000 postos entre os anos de 2005 e 2015, tem-se uma retração de igual magnitude somente no período 2015/2017. Em contrapartida, aumenta a oferta de empregos nos setores de serviços e comércio, o

\footnotetext{
${ }^{6}$ Vale frisar que o termo é tomado enquanto conceito científco, referendado por órgãos governamentais e atinentes a espaços considerados indignos para o desenvolvimento social e econômico. Para melhor compreensão ver Relatório IPEA 2012, Distribuição dos aglomerados Subnormais na Rede Urbana e Grandes Regiões Brasileiras.
} 
que poderia sugerir, entretanto, uma espécie de distorção em relação à vocação econômica recente do município.

Ao lado dos desafios já citados, há outro, que ocupa lugar cada vez mais central na vida dos brasileiros: a violência (SOARES, 2006). Vista, durante muito tempo, como um fenômeno típico das metrópoles, é observável que a violência (em suas mais diversas variantes e condicionantes) venha se impondo como realidade para cidades que, até duas décadas, a tinham como um evento episódico.

Segundo o Mapa da Violência (2015), entre os dez municípios brasileiros, com as maiores taxas médias de óbitos e homicídios por arma de fogo (AF), encontramos apenas uma capital: Maceió, ocupando a nona posição. O surgimento dos novos polos da violência no Brasil teria, segundo Beato (1999) e Soares (2006), causas variadas. Uma delas, talvez a mais ajustada ao caso de Angra dos Reis, atine ao florescimento de novos polos de desenvolvimento econômico que terminam atraindo grandes contingentes de trabalhadores migrantes, em intervalos de tempo, relativamente, curtos. A fragilidade dos municípios de pequeno porte - face as dificuldades de transformar a arrecadação em benefícios diretos e indiretos aos contribuintes - em atender as demandas impostas por esse novo contingente, terminariam por produzir aumento do número de pessoas em situação de vulnerabilidade e, por conseguinte, mais suscetíveis ao assédio do crime, em especial o tráfico de drogas, dado suas feições de "crime-negócio" (ZALUAR, 2007). Tal como resume o Mapa da Violência $(2015$, p.55):

"[Consolida-se], durante a década de 1990, um processo de desconcentração econômica que origina a emergência de novos polos, que atraem investimentos, trabalho e migrações. Somado a esse processo, as deficiências e insuficiências do aparelho do Estado e da Segurança Pública contribuem para a atração da criminalidade e da violência nesses novos polos".

A emergência de novos polos produtivos, uma vez relacionada à migração de mão de obra suscitaria o desenvolvimento de uma gama de políticas sociais, voltadas, principalmente, para as camadas mais sensíveis ao impacto do desemprego. Trata-se de uma equação simples. No caso angrense, partindo da premissa que as características socioeconômicas do município o coloquem na condição de "suscetível ao crescimento da violência", a situação seria ainda mais delicada, diante das oscilações do setor da construção naval, observadas entre os anos 1980/2000. Conforme indicam as especialistas em políticas tecnológicas Claudiana Jesus e Leda Gitahy (2010, p. 3903): 
"A instalação do estaleiro holandês Verolme (anos 1960) modificou totalmente a dinâmica econômica de Angra dos Reis. Com a crise da indústria naval chegou a se tornar um espaço-fantasma. Em 1999, impulsionado pela retomada do setor, o consórcio Fels Setal (controlado pelos grupos Keppel Fels, de Cingapura, e Pem Setal, do Brasil) reativou o Verolme, rebatizado como Brasfels em março de 2000".

Apesar do possível alinhamento da dinâmica criminal da cidade de Angra dos Reis com condicionantes causais como crescimento populacional não planejado, associado às oscilações e debilidades de setores específicos da atividade produtiva (como a indústria naval), observa-se o recrudescimento de um discurso, em particular: a associação do aumento da violência no município à migração de marginais (traficantes) das favelas ocupadas pelas UPPs, na capital.

Antes de avançarmos, é preciso, porém, observar alguns pontos. Primeiramente, há de ressaltar, que a denúncia da migração de traficantes do Rio para comunidades do interior do estado não se restringe ao caso angrense. Já em 2012, o Secretário de Turismo de Búzios (Região dos Lagos), por exemplo, vinha a público denunciar que a atividade turística da cidade estaria sendo afetada por criminosos evadidos das favelas ocupadas pela polícia ${ }^{7}$

Em segundo lugar, faz-se mister questionar a plausibilidade do argumento. Angra viveria uma crise de segurança pública provocada pela migração de traficantes vindos de favelas cariocas ocupadas pelas UPPs. Mas o que diriam os números da segurança municipal a respeito?

Por fim, cabe perscrutar quais as implicações da produção e reprodução dessa "verdade" sobre a administração municipal e, em particular, sobre a gestão das políticas públicas de caráter preventivo no campo da segurança. O presente artigo propõe-se a oferecer respostas às duas últimas perguntas.

\section{Desmistificando o "efeito UPP" ou As ilusões do Éden: notícias do avanço da criminalidade na imprensa angrense}

"Violência explode em Angra e chega à Ilha Grande". Essa foi a chamada de uma matéria noticiada pelo Jornal "Maré", em 23 de setembro de 2016. Um casal de turistas de São Paulo, numa suposta tentativa de assalto, foi agredido a golpes de facão numa trilha na Ilha Grande. A jovem Raquel Araújo, de 27 anos, morreu no local. Seu acompanhante, Ítalo Almeida, encontrava-se hospitalizado, após ser atendido pelo serviço de médico de urgência.

A matéria era enfática ao determinar as causas do crescimento da violência na região: as UPPs da capital! Tomemos uma passagem ipsis litteris: "É triste a constatação do que Angra dos

${ }^{7}$ Ver O Globo, 16 de março de 2012. 
Reis se tornou nos últimos anos, principalmente após a instalação das UPPs nas favelas carioca (sic) o que fez com que bandidos da capital, procurassem refúgio nas cidades do interior" (Maré, 23/09/2016).

O fim dos "tempos de paz" é reproduzido em outra matéria, onde é noticiada uma onda de assaltos, ocorrida no início do mês de dezembro do mesmo ano. Na primeira página, em letras garrafais lê-se: “Angra dos ladrões”. Segue o texto: “Que Angra dos Reis não é mais aquela cidade pacífica de outros tempos todo mundo já percebeu, mas a ousadia dos bandidos em três assaltos realizados nos últimos dias, ainda surpreendeu e apavorou muita gente” (Maré, 9/12/2016).

O caderno "Maré Opinião", na sua coluna "Papo de Esquina", traz o jornalista João Carlos Rabello, em artigo intitulado “O Alemão é aqui”. Sua análise sobre a expansão da violência em Angra segue as pistas das notícias anteriores. Uma mecânica simples: a pacificação da capital teria por tributo o fim da tranquilidade das cidades do interior. Nas suas palavras:

“(...) Quando o tráfico começou a agir em Angra, tomando as rédeas do bairro Belém, a maioria das pessoas nem se preocupou. Quando se espalhou para a Japuíba, ainda se tolerou, apesar da tragédia para os moradores do bairro. Depois, homens armados viraram rotina na Sapinhatuba e ainda assim acharam que estavam confinados a um gueto.

Agora cada morro do Centro de Angra, em cada bairro em todos os distritos, há uma boca do tráfico dando ordens através das armas. No Morro do Peres queriam cobrar pedágio para político fazer campanha.

Culminando com os tumultos no Morro da Caixa D'água e no Frade, no dia 1. de novembro, Angra agora imita o Complexo do Alemão e [a] Rocinha, de onde boa parte dos traficantes fugiu para o interior com a instalação da Unidade de Polícia Pacificadora (UPP).

Só que agora o estado está falido. Sem dinheiro para grandes mobilizações policiais, negocia-se uma ação permanente de policiais da Força Nacional para auxiliar o combate ao crime no Rio de Janeiro. Seria uma boa hora de pedir intervenção federal. Também aqui em Angra com os agentes sediados no colégio Naval ${ }^{8 \%}$. (Maré, 4/9/2016).

Ao longo da pesquisa, o registro das ocorrências criminais publicadas na imprensa contou com a catalogação de exemplares dos dois jornais locais de maior circulação: Jornal Maré e Jornal A Cidade. Tal como ilustra o Quadro 01, os registros do Jornal A Cidade são mais numerosos, o que não nos impede de notar que ambas as publicações seguem uma linha editorial calcada no jornalismo policial de apelo sensacionalista e mórbido. Não raro, são fotos de cadáveres crivados de

\footnotetext{
${ }^{8}$ Grifos meus.
} 
tiros e corpos mutilados que adornam a narrativa textual. A morte violenta é denunciada e espetacularizada, simultaneamente.

As 213 matérias foram divididas em seis categorias: "Crimes passionais, violência sexual e rixas"; "Crimes de motivação indeterminada"; "Atividade policial"; "Crimes contra o patrimônio"; “Ações do tráfico" e "Perturbação da ordem".

\section{Quadro 01}

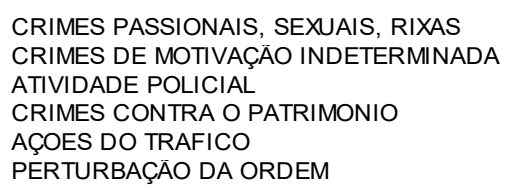

$\begin{array}{cc}\text { A CIDADE } & \text { MARE } \\ 10 \\ 22 \\ 42 \\ 30 \\ 20 \\ 1\end{array}$

O levantamento feito entre os meses de setembro e dezembro de 2016, tinha como objetivo inicial, apenas, orientar os pesquisadores no universo da dinâmica criminal angrense, todavia, revelou-se um tanto mais promissor. Coincidentemente, o período casava com dois eventos que viriam a aquecer o debate público sobre segurança. Em setembro, estabelecera-se uma disputa pelos pontos de venda de drogas nos morros de Santo Antônio e Caixa D'Água, situados na região central da cidade. O conflito tinha como pivô o traficante "Coroa", supostamente evadido do subúrbio do Lins dos Vasconcelos na capital, onde fora instalada uma UPP no ano de 2013. Em novembro, por sua vez, o bairro do Frade foi atacado por criminosos oriundos da Favela de Antares (Zona Oeste do Rio) numa disputa entre facções rivais pela hegemonia do tráfico de entorpecentes na região.

\section{Notícias da invasão do Morro da Caixa d'Água e de Santo Antônio}

Segundo matéria publicada pelo Jornal A Cidade (16/9/2016), sob o título de "Xeque-mate do chefão", a morte de uma jovem conhecida como Ariela encobriria uma disputa interna de uma facção criminosa pelo controle do tráfico nos morros da Caixa D'Água e de Santo Antônio. Tem-se:

\footnotetext{
"De acordo com informações, o que parece com uma vingança ou "justiça" pela morte da jovem é nada mais nada menos que uma disputa por território. No último dia 9, aproximadamente 15 marginais do Complexo do Lins, Zona Norte do Rio, subiram o Morro do Santo Antônio para executar Seco, Dikombi e Marlon. Eles teriam se juntado "as crias" (sic) da comunidade, Tatinha, "GT" e Douguinha para fazer o "serviço" a mando do chefão Coroa, que quer comandar as bocas de fumo dos nove morros do Centro.
} 
Os bandidos teriam chegado bem armados e trazendo carregamento de drogas para vender na comunidade. $\mathrm{O}$ chefão Coroa, que teria mandado matar Leandro de Souza Soares, de 34 anos, vulgo LD, ex-chefe do tráfico no Morro da Caixa D'Água e Vitor Nejo Ferreira, 35 anos, gerente do tráfico no Santo Antônio, em julho, teria visto o lucro alto das bocas de fumo. Mas no seu caminho estava Seco, Dikombi e Marlon, que trabalhava para o bandido Dr. Bola, e justificando as execuções, aplicando uma lei da facção ele pode tomar os pontos de venda. Dando assim um xeque-mate dentro da própria organização criminosa (...).

Depois do triplo homicídio, os marginais se esconderam na mata, onde ficaram até a saída da força policial do Santo Antônio. Mais tarde voltaram para seus postos de costume (...). Traficantes do Lins permanecem no morro".

O Jornal Maré (16/9/2016) também noticiou o fato, salientando que:

“(...) O Morro de Santo Antônio vem sofrendo com o tráfico de drogas, e bandidos que fugiram de áreas ocupadas no Rio ${ }^{10}$ têm tido facilidade de se adaptarem no local, uma vez que a topografia da comunidade permite rápida fuga pela mata".

Menos de um mês depois, novos eventos ocorrem no Morro da Caixa D'Água, reavivando o drama da migração dos criminosos do Rio. A chamada gritante faz jus à gravidade dos fatos: "Meninas podem ter sofrido estupro coletivo no Morro da Caixa D'Água". Desenvolve-se a matéria do dia 7/12/2016:

"Uma menina de 12 anos e uma adolescente de 15 anos teriam sido espancadas e abusadas sexualmente durante a noite do dia 29 e parte da madrugada do dia 30, no Morro da Caixa D'Água. De acordo com uma fonte do Jornal A Cidade, cerca de 12 traficantes teriam estuprado as jovens por horas, como forma de castigo.

As jovens teriam sido torturadas e muito espancadas. Depois do ocorrido, ambas não foram mais vistas e permanecem trancadas dentro de casa com medo. No entanto, os traficantes ainda estariam decidindo o que fazer com as jovens (...). Apesar do caso ser de conhecimento dos moradores da parte alta, não houve registros do fato na delegacia.

Há meses a comunidade sofre com uma infestação de traficantes de drogas do Complexo do Lins, na Zona Norte do Rio de Janeiro que viram nos Morros da Caixa D'Água e do Santo Antônio uma fonte lucrativa. O abuso e a certeza de impunidade são tão grandes que na Rua Salomão Reseck, os traficantes montaram uma boca de fumo em frente a uma padaria. No local eles dispõem de luz, comida, um sofá, cadeiras e mesa. A noite o funk proibidão rola a solta, tiros são disparados sem motivo e a venda de drogas é 24 horas".

Ainda no mês de outubro, a série de eventos ganha novo episódio. O Jornal A Cidade, do dia 28 de outubro de 2016, anuncia: “Chefão do Morro da Caixa D'Água é preso no Lins".

\footnotetext{
${ }^{9}$ Grifos meus.

${ }^{10}$ Grifos meus.
} 
"Vanderlei Gilberto Lopes, vulgo Paizão ou Coroa, como é conhecido em Angra, foi preso pela Polícia Militar na tarde do dia 23, no Complexo do Lins, Zona Norte do Rio de Janeiro, De acordo com os policiais, é comum traficantes possuírem vulgos diferentes em cada comunidade que atuam. Paizão ou Coroa ainda era conhecido como Vandão. Ele é apontado como chefe do tráfico de Drogas no Morro do Amor, no Lins e chefe do tráfico no Morro da Caixa D'Água (...). A Polícia Civil do Rio investiga a participação de Paizão em um assalto a uma joalheria de um shopping na Zona Oeste. O marginal seria um sócio dos assaltantes, cedendo armas e veículos. Em troca, os traficantes recebiam metade dos lucros dos assaltos. O crime aconteceu em agosto e os bandidos levaram mais de R 3 milhões em joias.

(...) Ainda de acordo com informações, traficantes do Complexo do Lins permanecem nos Morros da Caixa D'Água e Santo Antônio, comercializando drogas livremente na Rua Salomão Reseck. Anunciando os diferentes tipos de drogas como se vendessem frutas numa feira livre. No alto do morro, entre as duas comunidades, os traficantes teriam criado uma espécie de acampamento. Fortemente armados, andam pelos morros e não escondem de ninguém o que fazem, vários menores são recrutados e aqueles que sabem atirar viram "soldados" da facção criminosa que atua em ambas as comunidades. Informações também dão conta de que o bando de Coroa teria expulsado várias pessoas de bem das comunidades que não concordavam com o tráfico. Também comentam que toda a parte alta do Santo Antônio, onde várias casas foram interditadas depois da tragédia das chuvas de 2010 foram transformadas em quartel general do tráfico (...). Com a prisão de Coroa, ninguém sabe até agora quem vai continuar mandando na região".

\section{Notícias da invasão do Frade}

No início de novembro, foi a vez do bairro do Frade sofrer com as investidas de criminosos vindos do Rio de Janeiro. Além da ocupação em si, aparentemente, o ataque ao bairro do Frade constituir-se-ia uma ação estratégica empreendida pelos traficantes de uma mesma facção visando o fortalecimento regional e a consolidação futura, em âmbito nacional. O título da matéria é sugestivo: "Sob o domínio do mal".

"Na semana passada, uma das facções criminosas que mais cresce no país teria conseguido tomar de vez o tráfico de drogas no Frade. Uma intensa troca de tiros entre traficantes na tarde do dia primeiro assustou moradores e provocou sensação de insegurança por toda a cidade.

Traficantes da favela de Antares, no Rio, teriam invadido o Morro da Constância para tomar o comando das bocas de fumo da facção rival, que ainda comnada o tráfico no Areal, Monsuaba, Lambicada, Belém e Sapinhatuba 1 e 2.

Os traficantes cariocas teriam tido o apoio "dos crias" do Areal, Camorim Grande, Morro da Glória e até do Parque Mambucaba (comunidades dominadas pela mesma facção).

A facção que tomou Frade possui uma conhecida caixinha de fuzil. As comunidades que tem a caixinha têm acesso aos armamentos e a ajuda da "família" 
para confrontos como o da semana passada. O conflito deixou dois mortos, que seriam soldados da facção rival, e dois feridos, entre eles um policial militar.

Segundo informações a facção, que teve formação na prisão Cândido Mendes, na Ilha Grande em 1979, estaria se fortalecendo e fechando bairro que ficam nas divisas da cidade, vistos como estratégicos para a entrada de drogas e armas na região (...)”. (Jornal A Cidade, $11 / 11 / 2016)$.

As narrativas dos jornais locais não poderiam ser mais diretas em evidenciar a dramaticidade da dinâmica do tráfico de drogas sobre a vida da população, em particular dos moradores das favelas. Percebe-se, porém, que há uma imbricada trama de atos violentos que passa pelas disputas internas de poder dos criminosos, dentro de suas fações, até estratégias mais amplas, que objetivam facilitar a entrada de armas e drogas nos domínios deste ou aquele grupo.

Fica igualmente claro que o exercício do poder do tráfico altera, radicalmente, o cotidiano e o senso de normalidade. A ditadura do medo transforma em rotina delitos de diferentes naturezas, da invasão de propriedade até o estupro, passando pela perturbação da ordem e pelo homicídio.

O que não fica claro em tais narrativas é a relação de causalidade entre as ocorrências e a instalação das UPPs no Rio. Como sugere a série de notícias sobre a invasão do Morro da Caixa D'Água e Santo Antônio, o fator decisivo para a migração dos traficantes de Antares é o lucro estimado diante da possibilidade do monopólio das bocas de fumo da região do Centro da cidade e não a fuga desesperada da capital em função do recrudescimento das ações policiais das UPPs.

O mesmo se aplicaria ao caso da ocupação do Frade. As motivações seriam de ordem estratégica. O objetivo da invasão passaria pelo controle das artérias rodoviárias, por onde circulam armas e drogas. O fim último seria o fortalecimento de um sistema de alianças (a caixinha do fuzil), que tanto inibiria as fissuras internas como fortaleceria o bando diante das facções inimigas, incluindo as de outros estados.

A verificação da instalação das UPPs na capital como "variável independente" (ou não) do crescimento da violência em Angra dos Reis, pode ser realizada, contudo, com maior acuidade se investigarmos alguns números da criminalidade violenta no município, em cenários antes e pós pacificação.

\section{Criminalidade violenta em Angra dos Reis: alguns números}

Antes de prosseguirmos é crucial esclarecer alguns aspectos de ordem metodológica. Por tratar-se de uma pesquisa ainda em andamento, trataremos de comparações do tipo pré/pós instalação das UPPs na capital apenas para números absolutos e taxas relacionados à criminalidade violenta. 
Nesse sentido, não partimos da premissa (embora ela não seja descartável) que uma suposta migração de criminosos evadidos das favelas onde foram instaladas as UPPs, no sentido Rio-Angra, viesse a produzir aumento das modalidades de criminalidade não diretamente relacionáveis ao tráfico de drogas. Logo, os crimes contra o patrimônio, por exemplo, são desconsiderados nesse trabalho.

Para os propósitos deste artigo, trataremos, especificamente, de homicídios e óbitos por Arma de Fogo (AF) (taxas médias por 100.000 habitantes) e da série histórica do número absoluto de homicídios e apreensões de drogas no período (2006 [pré-UPP]-2009/2016 [pós-UPP]). Os dados referentes aos óbitos e homicídios estão condensados no formato de taxa média com intuito de minimizar as variações ano a ano, observadas, principalmente, no caso de municípios menos populosos.

As análises das taxas médias de homicídios e óbitos por AF (por 100.000 hab.) talvez seja o dado mais surpreendente aos adeptos do discurso da "crise de segurança" de Angra dos Reis. Como registra o Gráfico 01, as taxas em Angra, assim como na capital, vêm caindo progressivamente, sendo observado movimento inverso nos outros municípios da Região Costa Verde.

\section{Gráfico 01}

\section{Taxa Média de Obitos e Homicídios por AF/100Mil}

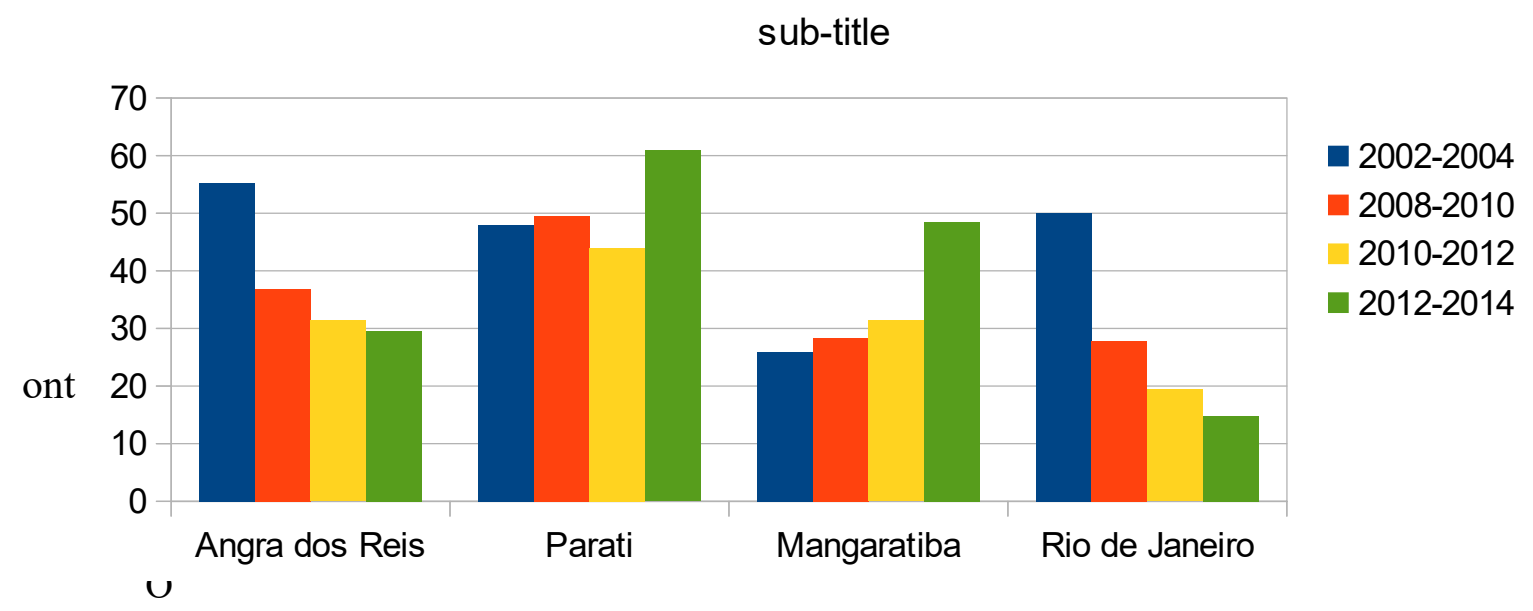

Fonte: Mapa da violência/ FLACSO

Gráfico 02 é ilustrativo em destacar que no início do século, reconhecidamente um momento crítico nas políticas de segurança do estado do Rio de Janeiro, as taxas de óbitos por AF, nos municípios de Angra, Parati e Rio de Janeiro (capital) eram aproximadas. O Quadro 02, que 
trata do posicionamento no ranking nacional das mortes por AF, confirma a tendência já apresentada. Enquanto Parati e Mangaratiba se aproximam, na série histórica das posições iniciais, Angra e a capital se distanciam.

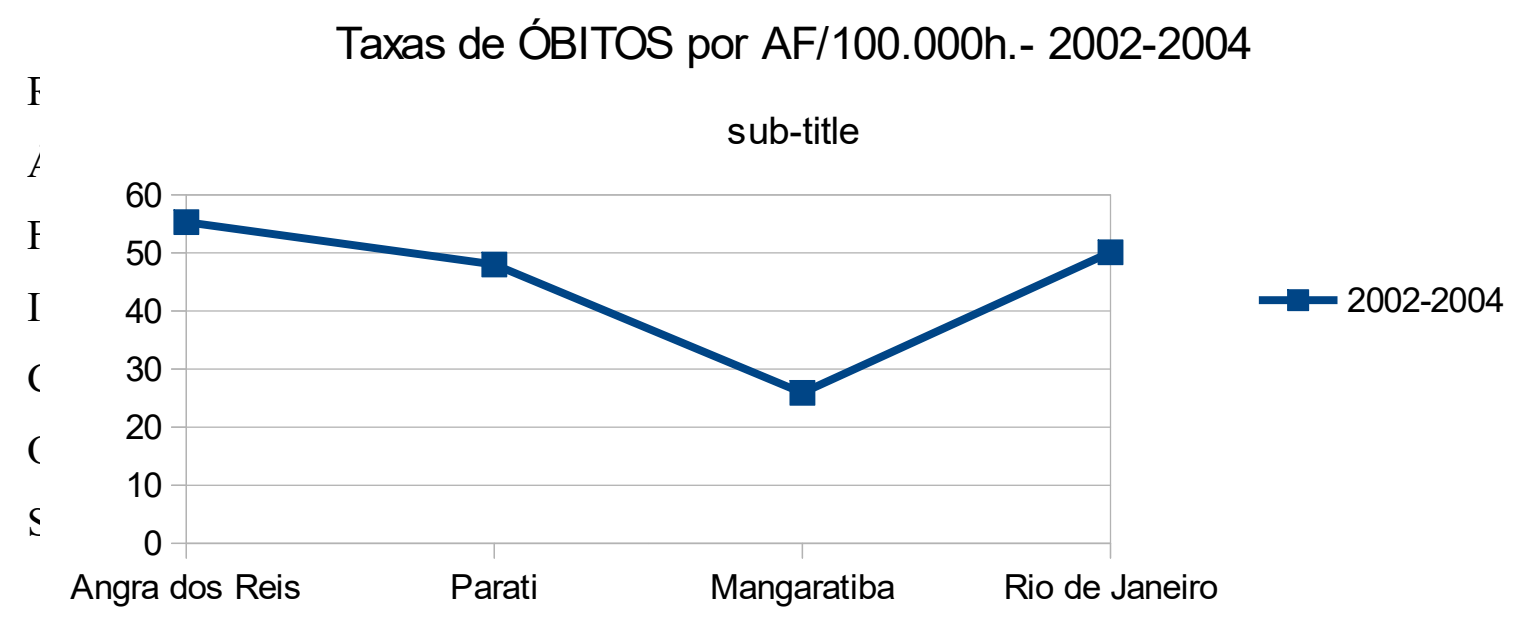

Fonte: Mapa da Violência/FLACSO

Quadro 02

\begin{tabular}{|c|c|c|}
\hline \multicolumn{2}{|c|}{ Posições no ranking nacional de mortes por AF } \\
\hline Região/Ano & $2002-2004$ & $2012-2014$ \\
\hline Angra & $45^{\circ}$ & $402^{\circ}$ \\
\hline Parati & $81^{\circ}$ & $48^{\circ}$ \\
\hline Mangaratiba de Janeiro & $387^{\circ}$ & $111^{\circ}$ \\
\hline $\begin{array}{l}\text { Rio de } \\
\text { (Capital) }\end{array}$ & $70^{\circ}$ & $969^{\circ}$ \\
\hline
\end{tabular}

Fonte: Mapa da Violência/FLACSO

Ao analisar os números absolutos dos homicídios e das apreensões de drogas, encontramos algumas tendências similares. No caso dos homicídios, ao longo do intervalo 2006-2016, temos um aumento percentual da ordem de 39,1\%. O volume de apreensões de drogas é elevado, entretanto, a patamares bem mais expressivos: 162\%. Há de se registrar que, no intervalo 2005-2015, a população angrense cresce em 34,1\%. Em ambos os casos é observável que o ritmo de crescimento se acelera, significativamente, entre os anos de 2012 e 2015. 
Gráfico 03

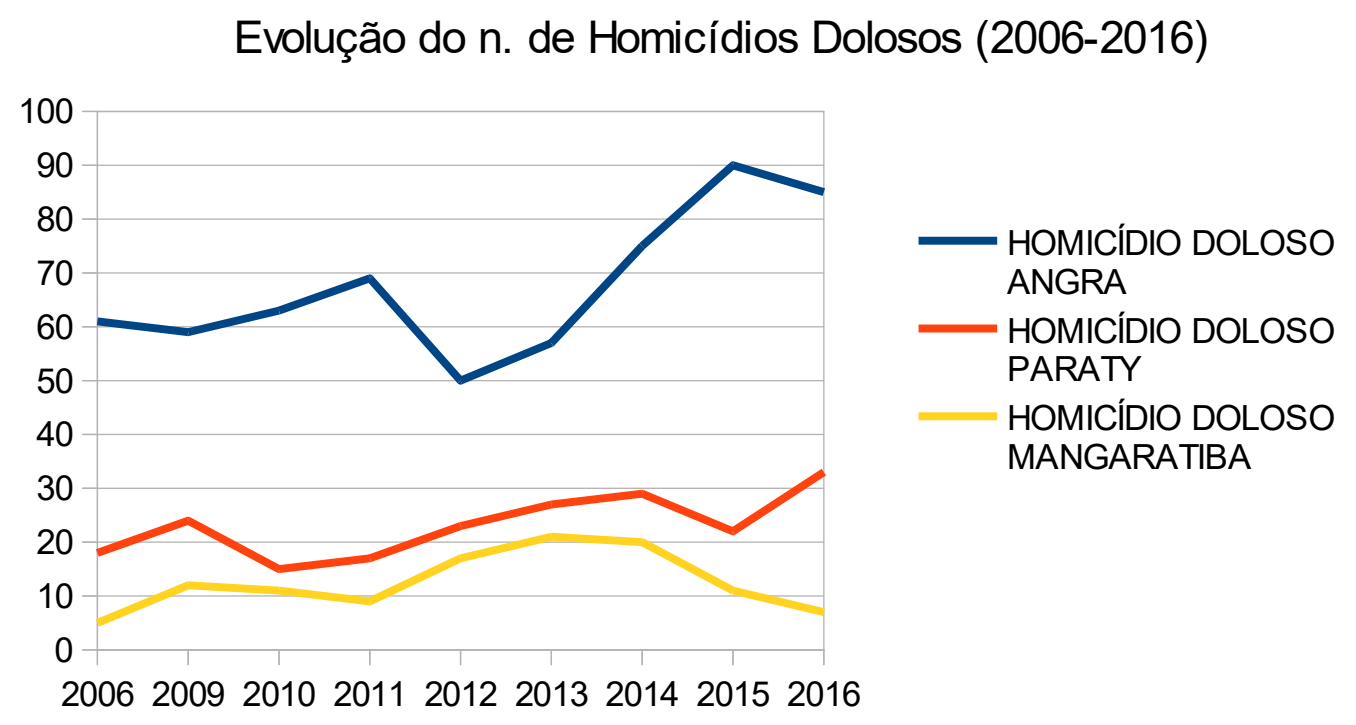

Gráfico 04

Evolução do n. de apreensões de drogas (2006-2016)

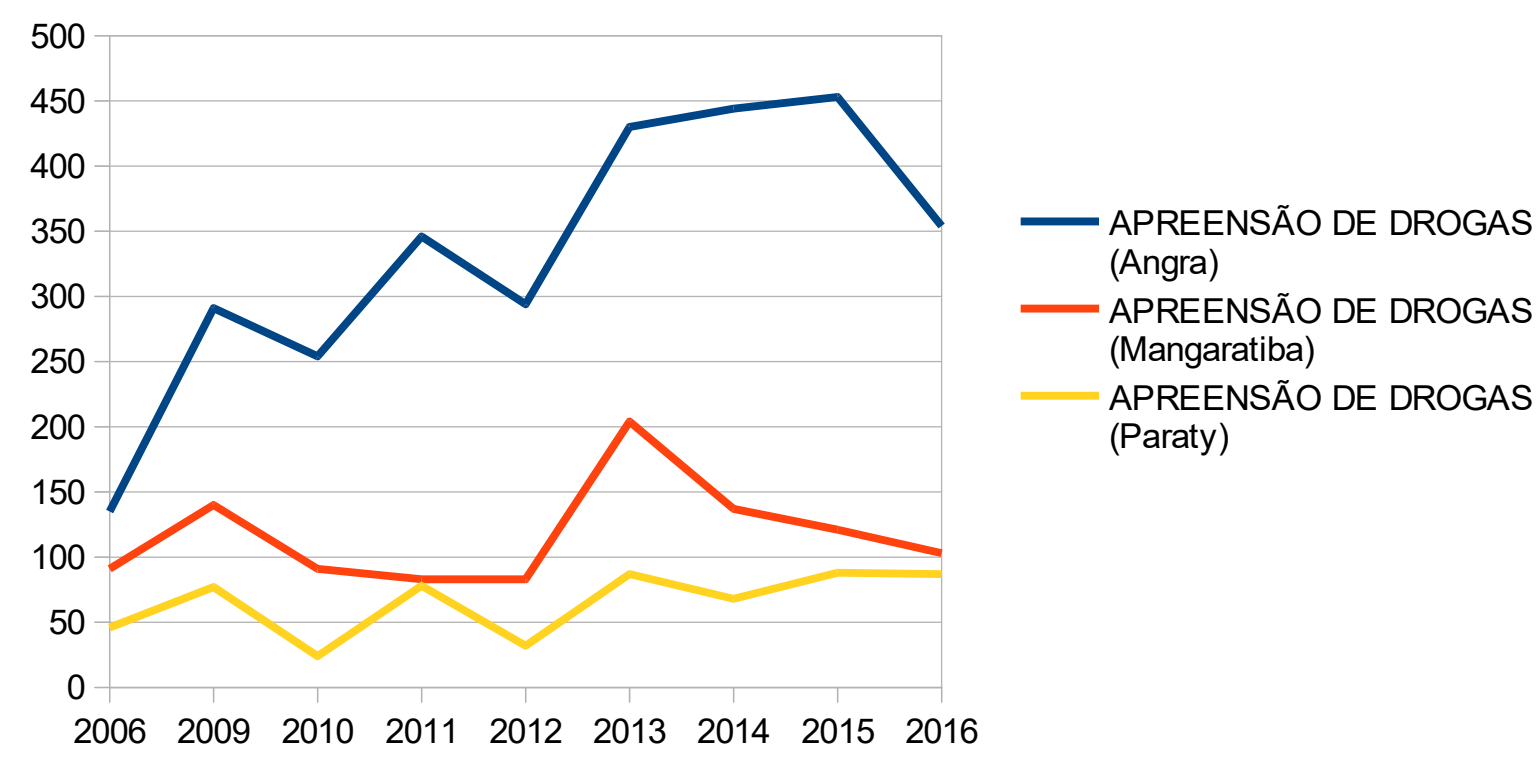

É certo que o crescimento do número absoluto de ocorrências de homicídios e de apreensão de drogas pode alterar a percepção da população sobre a magnitude da violência local. O papel da imprensa é decisivo neste aspecto. O reconhecimento de que "violência vende jornal", não esgota as problemáticas subjacentes ao tema: a construção heroica de personagens violentos, sejam eles 
policiais ou criminosos; a estigmatização da população favelada (cenário recorrente das mortes mais bárbaras e mais impactantes) e a disseminação de um medo, que, conforme nos alerta o antropólogo Pedro Bodê (mimeo), pode assumir contornos de irracionalidade.

Esse último ponto é particularmente caro, aos propósitos do artigo presente. Imaginar que a fonte de "todo o perigo" reside em uma única causa, já é algo bastante temerário. Quando identificamos essa fonte de forma equivocada ou distorcida, as consequências podem ser ainda mais graves!

Apontar a instalação das UPPs como a explicação padrão para o crescimento da violência é um exercício equivocado e perigoso. Errôneo porque os números apontam que a violência letal, quando tomada a partir de homicídios e mortes por AF, vem retroagindo nos últimos quinze anos. Claro que poderíamos tomar outros parâmetros. Claro que os números, apesar da queda são extremamente altos, quando tomamos por base, por exemplo, o Relatório UNODC Intentional Homicides, counts and rates per 100.000, ou nos damos conta das cifras dos países europeus. Porém, adotar o discurso de que o problema da segurança pública em Angra dos Reis, ou em outras cidades do interior fluminense, é um epifenômeno da instalação das UPPs é uma forma de eclipsar as responsabilidades que as municipalidades devem assumir, no novo contexto das políticas de segurança pública, preconizadas desde a Constituição de 1988.

\section{Ordálio ou o desafio da construção de uma agenda de ações preventivas em segurança pública no âmbito municipal (Considerações Finais)}

Nos últimos trinta anos, a sociedade brasileira vem acompanhando um crescimento vertiginoso dos níveis de criminalidade violenta. Fenômeno que a princípio se restringia às grandes metrópoles e que agora parece se disseminar, com vigor, por cidades do interior.

Ao longo desse processo, temos convivido com dois paradigmas de ação. Um deles se orientava pela crença de que só a solução dos problemas macroestruturais (redução da pobreza, distribuição mais equânime da riqueza, melhor qualidade do ensino, etc.) poderia se apresentar como saída eficaz ao problema.

O segundo, orientado pela lógica da redução das responsabilidades sociais do Estado e pela emergência de um sistema de controle e de repressão mais eficiente, inclinava-se ao uso dos recursos punitivos como solução (WACQUANT, 1999; GARLAND, 1999). Elege-se o sistema de justiça criminal e suas instituições como os recursos, eminentemente adequados, para a lide com os assuntos da violência e do crime. Clama-se por leis mais duras, mais policiais nas ruas e mais 
prisões. O protagonismo recai sobre as Polícias Militares, responsáveis pela manutenção da ordem urbana, cuja presença no espaço público é mais marcante.

Paralelamente à difusão destes dois paradigmas, a Constituição Federal (CF) de 1988 amplia o raio de competência dos municípios no desenvolvimento de diversas políticas públicas no campo da saúde, educação, cultura e assistência que terminam por apresentar grande potencial no campo da prevenção (MESQUITA NETO, 2004).

É bem verdade que as ações de caráter preventivo, ao passo que precisam ser valorizadas em toda sua amplitude (profissionalização e qualificação das polícias, programas de atenção a juventude em áreas de risco, gestão da informação sobre ocorrências criminais, etc.), necessitam, urgentemente, de sistematização e acompanhamento do seu impacto em nível local. Donde temos:

"Muitos programas de prevenção do crime e da violência desenvolvidos na América do Norte e na Europa Ocidental começam a ser adotados no Brasil, conforme mostra o levantamento de programas em desenvolvimento no Brasil apresentado na seção 7 deste relatório. Entretanto, no Brasil, estes programas ainda têm alcance limitado e são desenvolvidos sem o esforço de monitoramento e avaliação existente nos Estados Unidos e, em menor escala, na Inglaterra. Como não é possível ter certeza de que programas eficazes na América do Norte e na Europa Ocidental são também eficazes no Brasil, é importante monitorar e avaliar os programas desenvolvidos neste país, e promover a pesquisa e desenvolvimento de programas de prevenção do crime e da violência adequados às necessidades e especificidades do Brasil”. (MESQUITA NETO, 2004, p. 231).

Destarte, ganha espaço o papel e a responsabilidade das administrações municipais nos assuntos de segurança e, talvez, recentemente, a aposta institucional (que ainda não apresentou resultados concretos em todas as regiões do país) em ações intersetoriais, envolvendo a Polícia Militar; polícia judiciária, guardas municipais e órgãos do executivo municipal (no contexto dos chamados Gabinetes de Gestão Integrada) seja expressão dessa tendência.

Voltando aos casos noticiados pela imprensa angrense, observamos que, no lugar de uma “invasão de criminosos evadidos de UPPs", o que parece, de fato, ocorrer é uma combinação entre traficantes locais e outros vindos de fora, no intuito de atender necessidades estratégicas, definidas pelos comandos das facções criminosas. Tende-se a concluir que, os traficantes de fora não poderiam lograr êxito sem o apoio dos chamados "crias da comunidade". É o que dá a entender uma leitura mais exaustiva das páginas policiais de a Maré e $A$ Cidade. O registro correto a ser apontado não é que os "criminosos do Rio estariam invadindo Angra", mas sim que, os jovens naturais de Angra estariam se envolvendo, mais frequentemente com o mundo do crime.

Estudos relativamente recentes, desenvolvidos em outras cidades do interior do estado do Rio de Janeiro, supostamente, também impactadas pelo crescimento de algumas modalidades 
criminais, revelam que o sistema penitenciário, dada suas feições, contribuiria, fartamente, para que jovens que haviam praticados delitos pontuais e de menor gravidade (pequenos furtos, presos com quantidades irrisórias de drogas, etc.) terminem, durante o cárcere, se socializando com componentes das facções do tráfico. Uma vez em liberdade, o vínculo permanece e uma rede de reciprocidades entra em ação, capilarizando, no futuro, as ações dos traficantes da capital no interior. Corrêa et. al. (2012) nos ajuda(m) a compreender o processo:

“(...) essa divisão simbólica teria raízes na passagem dos criminosos locais (condenados por roubo e furto, principalmente) pelo sistema prisional da capital, onde é comum a "afiliação" a uma facção criminosa durante o período de cárcere, [j]ustificando a necessidade de construção de um presídio regional" (CORREA et al., 2012, p.42).

A antropóloga Alba Zaluar (2007) nos alerta que, em um contexto histórico de radicalização do consumo e de fragilização das instituições e das moralidades, os segmentos menos abastados particularmente, os jovens pobres - estariam mais sujeitos à sedução de atividades criminosas, principalmente daquelas pautadas pela lógica do "crime-negócio", tal como o tráfico de drogas, onde o dinheiro circula com facilidade e em grandes quantidades - ou, pelo menos em quantidades que atendem às expectativas dos "operadores da ponta".

Diante do caso das cidades com rápido crescimento populacional combinado a fluxos migratórios motivados pelas oportunidades de emprego (onde o caso de Angra dos Reis se encaixaria, formidavelmente), a autora destaca a situação particular das gerações mais novas: os filhos e filhas desses migrantes que, encontrar-se-iam, (a) desapegados aos laços morais e tradicionais que motivaram seus pais e (b) expostos a desejos e expectativas produzidas no mundo globalizado e que não necessariamente podem ser saciadas com os recursos materiais disponíveis. Em certo sentido, os argumentos de Zaluar remontam cenários já descritos por outros autores da sociologia urbana como Foote Whyte (2005) (em sua análise sobre os jovens de Little Italy) e Richard Sennett (2012) com "Rico" (personagem pedal de A Corrosão do Caráter). Resume a autora:

\footnotetext{
"Tampouco a urbanização muito rápida, além de não garantir emprego para todos os migrantes e, depois, para os seus filhos, não permite que as práticas sociais urbanas da tolerância e civilidade sejam assimiladas entre os novos habitantes das cidades. Entretanto, por conta dos processos já mencionados de crise da autoridade e de difusão das novas identidades e estilos juvenis globais, rapidamente corrói os valores morais tradicionais, já não mais interiorizados pelas novas gerações da cidade" (ZALUAR, 2007, p. 535).
} 
Seguindo as pistas dos estudos urbanos, Gilberto Velho (2004) propõe a noção de projeto para investigar não apenas o estilo de vida dos setores médios urbanos, mas para compreender como o individualismo e autonomia - inclusive a autonomia em relação às famílias de origem e a velhos preceitos morais - são elementos constitutivos do "estar no mundo" dos jovens desse estrato social.

Os resultados até o momento encontrados pela pesquisa, porém, não são animadores, no sentido de encontrarmos, recursos institucionais capazes, de forma, ampla e qualificada, a dar suporte social e emocional aos jovens angrenses vulneráveis, que por ventura se encontrem nessa espécie de "encruzilhada da contemporaneidade": entre sum mundo que fabrica desejos e necessidades, mas que, ao mesmo tempo, restringe, ferozmente, os recursos para satisfazê-los.

As conversas com operadores da rede de proteção social, fossem informais, fossem registradas como entrevistas, remetem a um conjunto de técnicos pressionados por uma demanda excessiva e recursos escassos. Não há projetos sociais claramente direcionados para os jovens criminalmente implicados e a rede (compreendida como malha cooperativa formada por órgãos governamentais da assistência social e entidades da sociedade civil, como ONGs, Igrejas e afins) apresenta-se bastante limitada. Para uma população de mais de 160.000 habitantes, conseguimos mapear apenas 12 instituições reconhecidas como parceiras da rede de proteção social, sendo três delas autarquias municipais.

A rotatividade dos operadores da rede de proteção é também um problema, tendo em vista que muitas famílias, principalmente aquelas em situação de vulnerabilidade extrema ou vítima de algum tipo de violência, demoram mais para estabelecer laços de confiança com os profissionais que trabalham no atendimento direto. Muitas vezes quando o laço é finalmente estabelecido, o profissional é remanejado ou trocado, por ser contratado em regime temporário.

As tentativas de inserção dos jovens vulneráveis no mercado de trabalho também não se apresentam muito promissoras. Quando são estabelecidas parcerias com empresas privadas, incluindo as do ramo off-shore, surge o problema da escolaridade mínima, pois é sabido que os jovens em situação de vulnerabilidade, não raro, não conseguem concluir seus estudos ou encontram-se defasados em relação à série escolar correta.

Por fim, a própria violência torna-se um empecilho às ações de atenção aos jovens em situação de risco (que sofrem violências, negligência ou têm seus direitos violados). É recorrente que, em função dos confrontos armados, o serviço de visitas domiciliares da assistência social precise ser suspenso ou remanejado. 
São muitos elementos que evidenciam que há muito ser feito pela administração municipal no sentido de ampliar os recursos de atenção às comunidades que se encontram sob o jugo da violência armada.

Proponho, neste artigo, que uma das faces mais perversas da disseminação do que chamei anteriormente de "mito do efeito UPP" é a inércia do poder público em se empenhar em ações que terão que ser desenvolvidas e acompanhadas, localmente, uma vez que o dito "problema da violência", longe de ser uma mazela "importada" da capital, faz parte, e pelo que tudo indica, há bastante tempo, da vida outrora tida como "edênica" da população angrense.

\section{Referências Bibliográficas:}

ABREU, Antônio Izaías da Costa. Municípios e Topônimos Fluminenses: Histórico e Memória. Niterói. Imprensa Oficial do Estado do Rio de Janeiro, 1994.

BEATO, C. Políticas Públicas de Segurança e a Questão Policial. São Paulo em Perspectiva, 13(4), pp. 13-27, 1999.

BOURDIEU, P. A Economia das Trocas Simbólicas. São Paulo (Coleção Estudos/20): Perspectiva, 2015.

CANO, I. 'Os donos do morro': Uma avaliação exploratório do impacto das Unidades de Polícia Pacificadora (UPPs) no Rio de Janeiro. 2012. Texto na Internet. Disponível em: http://www.lav.uerj.br/docs/rel/2012/RelatUPP.pdf

CORREA, R. et al. Diagnóstico de Segurança Pública de Itatiaia. Rio de Janeiro, Imagem e Texto, 2012.

GARLAND, David. As contradições da 'sociedade punitiva: o caso britânico. Revista de Sociologia Política. n.13, pp.59-80. Curitiba, 1999.

GITAHY, L.; JESUS, C. Transformações na Indústria de Construção Naval Brasileira e seus Impactos no Mercado de Trabalho (1997-2007). Apresentação no Segundo Congresso Lusófono de Desenvolvimento Regional. Cabo Verde, 2010.

MACHADO, L. A. Afinal, qual é das UPPs? Observatório das Fevelas. Disponível em: http://www.observatoriodasmetropoles.ufrj.br/artigo_machado_UPPs.pdf

MAPA DA VIOLÊNCIA, 2015. São Paulo/Flasco, 2015.

MESQUITA NETO, P. Prevenção do Crime e da Violência e Promoção da Segurança Pública no Brasil. In: Arquitetura Institucional do Sistema Unico de Segurança Pública. SENASP, 2004. RIO DE JANEIRO: TCE/FIRJAN, Estudos Socioeconomicos dos Municípios Fluminenses, 2015.

SENNETT, R. A Corrosão do Caráter. Rio de Janeiro, Best Bolso, 2012. 
SOARES, Luiz E. Segurança Pública: presente e futuro. Estudo Avançados 20(56), pp. 91-105, 2006.

VELHO, G. Individualismo e Cultura. Rio de Janeiro, Zahar, 2004.

WACQUANT, L. As prisões da miséria. Rio de Janeiro: Zahar, 1999.

WHYTE, W.F. A Sociedade de Esquina. Rio de Janeiro, Zahar, 2005.

ZALUAR, A. Polícia e Juventude na Era da Globalização. In: BLANCO, C. e CARUSO, H. (Orgs). Polícia e Sociedade. Rio de Janeiro. Imagem e Texto, 2007.

Recebido em: Maio de 2018

Aprovado em: Julho de 2018 